\title{
Decreased expression of APAF-I and increased expression of cathepsin B in invasive pituitary adenoma
}

\author{
Cristiana Tanase' \\ Radu Albulescu',2 \\ Elena Codrici' \\ Bogdan Calenic ${ }^{1,3}$ \\ Ionela Daniela Popescu' \\ Simona Mihai' \\ Laura Necula ${ }^{1,4}$ \\ Maria Linda Cruceru ${ }^{5}$ \\ Mihail Eugen Hinescu ${ }^{1,5}$ \\ I"Victor Babes" National Institute of \\ Pathology, Biochemistry-Proteomics \\ Department, ${ }^{2}$ National Institute \\ for Chemical Pharmaceutical R\&D, \\ 3"Carol Davila" University of \\ Medicine and Pharmacy, Department \\ of Biochemistry, ${ }^{4}$ Stefan S. Nicolau \\ Institute of Virology, Cellular and \\ Molecular Pathology, "'Carol Davila" \\ University of Medicine and Pharmacy, \\ Cellular and Molecular Medicine \\ Department, Bucharest, Romania
}

Correspondence: Cristiana Tanase "Victor Babes" National Institute of Pathology, no 99- I0I Splaiul Independentei, 050096, Sector 5

Bucharest, Romania

$\mathrm{Tel}+40213194528$

$\mathrm{Fax}+40213194528$

Email bioch@vbabes.ro
This article was published in the following Dove Press journal:

OncoTargets and Therapy

22 December 2014

Number of times this article has been viewed

Purpose: Apoptotic protease-activating factor-1 (APAF-1) and cathepsin B are important functional proteins in apoptosis; the former is involved in the intrinsic (mitochondrial) pathway, while the latter is associated with both intrinsic and extrinsic pathways. Changes in the expression of apoptosome-related proteins could be useful indicators of tumor development since a priori defects in the mitochondrial pathway might facilitate the inception and progression of human neoplasms. Our aim was to evaluate the profiles of APAF-1 and cathepsin B in relation with other molecules involved in apoptosis/proliferation and to correlate them with the aggressive behavior of invasive pituitary adenomas.

Materials and methods: APAF-1 and cathepsin B were assessed in tissue samples from 30 patients with pituitary adenomas, of which 16 were functional adenomas and 22 were invasive adenomas.

Results: A positive relationship between high proliferation and invasiveness was observed in invasive pituitary adenomas when compared to their noninvasive counterparts (Ki-67 labeling index $-4.72 \%$ versus $1.75 \%$ ). Decreased expression of APAF-1 was recorded in most of the invasive adenomas with a high proliferation index, while the cathepsin $\mathrm{B}$ level was elevated in this group. We have noticed a negative correlation between the low level of APAF-1 and invasiveness $(63.63 \% ; P<0.01)$; at the same time, a positive correlation between cathepsin $\mathrm{B}$ expression and invasiveness $(59.09 \% ; P<0.01)$ was found. In all, $81.25 \%$ out of the total APAF-1-positive samples were cathepsin B negative $(P<0.01) ; 76.92 \%$ out of the total cathepsin B-positive samples were APAF-1-negative $(P<0.01)$. These results were reinforced by an apoptosis protein array examination, which showed inhibition of the extrinsic apoptotic pathway in an invasive pituitary adenoma.

Conclusion: A bidirectional-inverted relationship between APAF-1 and cathepsin B expressions was noticed. One might hypothesize that shifting the balance between mediators of cell death could result in changes in tumor behavior.

Keywords: apoptosis, pituitary adenoma, APAF-1, cathepsin B, Ki-67, p53

\section{Introduction}

Pituitary adenomas (PAs) are common tumors of the pituitary gland, accounting for approximately $15 \%$ of total primary intracranial tumors. ${ }^{1-6}$ While most of the PAs are known to exhibit slow growth, approximately one-third of PAs can exhibit an aggressive behavior, characterized by fast invasive cell growth, followed by subsequent invasion of the surrounding tissues. The underlying biological processes that trigger the invasive behavior of PAs include the balance between proliferation and apoptosis. ${ }^{7-9}$ Because of the limited number of studies, little is known about the regulation and significance of apoptosis in PAs. ${ }^{8,10-12}$ 
The ability to maintain a balance between the rate of proliferation and programmed cell death is of paramount importance in regulating tissue homeostasis and organ architecture. Disruption of this equilibrium is closely connected to the commencement and development of many types of cancers, and it represents a valuable target for antitumor therapy. ${ }^{13,14}$ Several markers have been shown to correlate apoptosis or proliferation with the biological features of tumor cells. Thus, the World Health Organization refers to Ki-67 and p53 as potential indicators of aggressive behavior of PAs. ${ }^{15}$ Previous studies examined the hidden correlations between $\mathrm{p} 53$ and Ki-67 expression and the invasive features of PAs, but they did not reach a consensus. ${ }^{3,15,16}$ The available data suggest that these markers cannot function as independent prognostic factors of tumor invasiveness. Therefore, disclosure of new markers may highlight the relationship between the invasiveness, proliferation, and apoptosis in PAs. Although current results are not entirely consistent, it has been shown that apoptosis occurs with low frequency in PAs. ${ }^{17,18}$ The most important pathways involved in apoptosis are the intrinsic (or the mitochondrial) and the extrinsic (or the death ligand) pathways. Apoptotic protease-activating factor-1 (APAF-1) and cathepsin $\mathrm{B}$ are important components of these apoptotic pathways. ${ }^{19,20}$ On the one hand, APAF-1 is the main component of the apoptosome, a platform required for caspase 9 activation..$^{21}$ The induction of the intrinsic pathway involves both the release of cytochrome $\mathrm{C}$ from the mitochondria, and the formation of the oligomeric apoptosome by binding with cytosolic APAF-1, deoxyadenosine triphosphate, and caspase 9. Further activation of other caspases leads to programmed cell death. ${ }^{22}$ Over- or underexpression of apoptosome-related proteins might be good indicators of tumor development, since a priori defects in the mitochondrial apoptotic pathway might favor the initiation and progression of human neoplasms. Deregulation of apoptosome has been demonstrated in various forms of human cancer, and it may play a role in both carcinogenesis and chemoresistance. ${ }^{23}$

Cathepsin B, a lysosome cysteine protease, was mostly studied in relationship with its overexpression in various cancers, degrading the extracellular matrix molecules and altering the balance between matrix metalloproteinases and their inhibitors. ${ }^{24}$ Overexpression of cathepsin B was found in brain tumors, especially high-grade gliomas, and it was also correlated with invasive cancer phenotype and poor prognosis due to its contribution to the change of the extracellular matrix. ${ }^{25}$ Knockout studies in mice related this protein with tumor necrosis factor (TNF) $\alpha$-induced apoptosis (the extrinsic pathway). ${ }^{26}$ Cathepsin B might be involved in malignant cell biology at different stages, ranging from tumor invasion, through to extracellular matrix degradation, to intracellular proteolysis. ${ }^{27}$

The roles of APAF-1 and cathepsin B in the development of PAs and their involvement as putative markers in proliferation or apoptosis are currently not well understood. The specific aim of the present study was to evaluate the profiles of APAF-1 and cathepsin B in relation to the other molecules involved in apoptosis/proliferation and to correlate them with the aggressive behavior of invasive PAs.

\section{Materials and methods}

\section{Patients and specimens}

PA tissue samples were obtained from patients undergoing surgical procedures at the Neurosurgical Unit of BagdasarArseni Hospital, Bucharest. Written informed consent was obtained upon sample prelevation according to the Declaration of Helsinki, and the study was approved by the local ethics committee. For each patient, clinical parameters such as age, sex, and radiological and histological exam of the PA's invasiveness state were collected. The study was performed on tissue samples from 30 patients with PAs, of which 16 adenomas were functional, and 22 adenomas presented invasive capacity. Tissue samples were formalin fixed and embedded in paraffin for immunohistochemical analysis. In order to perform the Proteome Profile Apoptosis Array, tissue samples were stored at $-80^{\circ} \mathrm{C}$ until analysis.

\section{Histopathology and immunohistochemistry}

The slides from paraffin-embedded tumor tissue ( $3 \mu \mathrm{m}$ thin) were stained with hematoxylin and eosin and were examined by light microscopy in order to establish the histological type of the adenoma and the extent of invasion in the neighboring tissue. Immunohistochemistry was performed on the paraffinembedded samples using the EnVision ${ }^{\mathrm{TM}}+$ Dual Link System Peroxidase kit (Dako Denmark A/S, Glostrup, Denmark), according to the manufacturer's instructions and following the protocol of our previous studies. ${ }^{7,27}$ Primary antibodies against the following antigens were used: p53 (clone DO-7, dilution 1:50; Dako Denmark A/S); Ki-67 (clone MIB-1, dilution 1:50; Dako Denmark A/S); APAF-1 (dilution 1:20; Leica Microsystems, Wetzlar, Germany); and cathepsin B (CB131, dilution 1:40; Leica Microsystems). APAF-1 and cathepsin B positivity was determined in the most active areas and immunoreactivity was established for each case, based on the percentage of cells showing positive staining and average staining intensity. The scoring used for the percentage 
of positive tumor cells was: 1 for $0 \%-25 \% ; 2$ for $26 \%-50 \%$; 3 for $51 \%-75 \%$; and 4 for $76 \%-100 \%$. The staining intensity was stratified on a scale of $0-3$ ( 0 for no staining, 1 for weak immunoreactivity, 2 for moderate immunoreactivity, and 3 for strong immunoreactivity). The intensity and percentage scores were then multiplied to obtain a composite score, ${ }^{28}$ which was defined as negative for scores $<6$ and positive for scores $>6$. Negative controls were processed by replacing the secondary antibody with phosphate buffered saline or by omitting the primary antibody.

\section{Protein extraction and apoptosis profile assessment}

The apoptosis-related proteins (including Bcl-2, Bax, Bad, procaspase-3, cleaved caspase-3, cytochrome C, TRAIL-R1/DR4, TRAIL-R2/DR5, FADD, Fas/TNFRSF6/CD95, HTRA2/Omi, p21/CIP1/CDKN1A, p27/Kip1, phospho-p53[S15], phosphop53[S46], phospho-p53[S392], phospho-Rad17[S635], SMAC/Diablo, survivin, and TNF-R1/TNFRSF1A) were measured using the Proteome Profiler Human Apoptosis array kit (R\&D Systems, Inc., Minneapolis, MN, USA), according to the manufacturer's instructions. Tissue samples were homogenized in lysis buffer with a $1 \%$ protease inhibitor cocktail (Sigma-Aldrich Co., St Louis, MO, USA). After 30 minutes of incubation on ice, the protein concentration was quantified using the Coomassie (Bradford) Protein Assay Kit (PIERCE). Equal amounts of proteins $(300 \mu \mathrm{g})$ from invasive and noninvasive tumor samples were incubated with the apoptosis array overnight at $4^{\circ} \mathrm{C}$. After the washing of unbound proteins, a detection antibody cocktail was added to the membranes and incubated for 1 hour. Finally, streptavidinhorseradish peroxidase and Chemi Reagent Mix were used to reveal apoptosis-related proteins by chemiluminescence. Array images were scanned using MicroChemi 4.2 (Berthold Technologies, Chennai, India) and analyzed by ImageJ software.

\section{Western blot}

Tissue lysates containing the same amount of protein $(25 \mu \mathrm{g})$ for each experimental condition were loaded on a $12 \%$ sodium dodecyl sulfate polyacrylamide gel electrophoresis gel. Electrophoresis was run at $20 \mathrm{~mA} / \mathrm{gel}$ and separated proteins were subsequently blotted on polyvinylidene fluoride membranes at $100 \mathrm{~V}$ for 90 minutes on ice. After overnight blocking with nonfat dry milk (5\%), membranes were incubated for 1 hour with primary antibodies: APAF-1 $(1 \mu \mathrm{g} / \mathrm{mL}$; R\&D Systems, Inc.), cathepsin B (1 $\mu \mathrm{g} / \mathrm{mL}$; Leica Microsystems), and $\beta$-actin ( $1 \mu \mathrm{g} / \mathrm{mL}$; Santa Cruz Biotechnology Inc., Dallas, TX, USA). After a 1-hour incubation period in suitable secondary antibody (goat antimouse, 1:10,000 dilution; Santa Cruz Biotechnology Inc.), membranes were incubated for 3 minutes in ECL solution (Thermo Fisher Scientific, Waltham, MA, USA) and exposed to film.

\section{Statistical analysis}

Differences between sample groups were analyzed using Student's $t$-test. Data were considered statistically significant at $P<0.05$. The chi-square test $\left(\chi^{2} ; P\right.$-value) was used to determine the significance of the association between APAF-1 expression, cathepsin B expression, and proliferation tumor markers or clinical parameters. Analyses were performed using SPSS 16.0 software (IBM Corporation, Armonk, NY, USA).

\section{Results}

During tumor development, a modified balance between proliferation and apoptosis occurs; we explored this altered equilibrium in PAs, as these tumors might become aggressive through their invasiveness. Our study examined several apoptotic molecules, mainly APAF-1 and cathepsin B, in correlation with the invasive behavior of these tumors.

\section{Conventional proliferation markers}

We noticed a positive correlation between proliferation activity - Ki-67 labeling index (LI) and invasive PAs when compared with their noninvasive counterparts (Ki-67 LI $4.72 \%$ versus $1.75 \% ; P<0.01$ ), using a threshold of $3 \%$ for $\mathrm{Ki}-67 \mathrm{LI}{ }^{29} \mathrm{~A}$ difference in $\mathrm{Ki}-67 \mathrm{LI}$ relating to functionality was recorded $-5.14 \%$ in functional versus $3.70 \%$ in nonfunctional adenomas $(P<0.05)$. In this study, p53 expression was found to be positive in 33\% of the analyzed PAs; p53 expression showed a significant positive correlation with the invasive status of these adenomas, with nearly $50 \%$ of the invasive specimens being p53 positive (Table 1).

Downregulation of APAF-I is associated with invasiveness in pituitary adenomas APAF-1 expression was downregulated in most invasive PAs; thus, out of the 22 invasive adenomas, 14 were APAF-1

Table I Correlation between $\mathrm{Ki}-67, \mathrm{p} 53$, and the invasive status of pituitary adenomas

\begin{tabular}{llllll}
\hline & Index & Invasive & Noninvasive & $\chi^{2}$ & P-value \\
\hline Ki-67 & $>3 \%$ & 20 & 0 & 17.175 & $<0.0$ I \\
& $<3 \%$ & 2 & 8 & & \\
p53 & + & 10 & 0 & 5.4545 & $<0.05$ \\
& - & 12 & 8 & & \\
\hline
\end{tabular}


negative $(63.63 \% ; P<0.01)$. In the other eight tissue specimens from low-grade invasive tumors, APAF-1 was expressed with a zonal distribution, but to different degrees (36.36\%) (Figure 1A-C). The results also showed differences for APAF-1 expression in relation to functional status. Out of 16 functional adenomas, eleven were downregulated for APAF-1 (68.75\%; P<0.01) (Table 2).

APAF-1 displayed very low expression in invasive adenomas. Since this protein plays a key role in the formation of apoptosome, its low expression "is reporting" for the modified apoptosis in aggressive tumors. This also correlates with the levels of pro-caspase-3 (lower in aggressive cases) and activated caspase-3 (lower in invasive adenomas), as well as with the levels of cytochrome $\mathrm{C}$, as revealed by dot blot analysis (as shown below).

\section{Overexpression of cathepsin B in correlation with invasive pituitary adenomas}

Our results showed that cathepsin B was commonly overexpressed in invasive PAs, showing a granular pattern, and mostly lying on the plasma membrane. Cathepsin B was overexpressed in 13 out of 22 invasive adenomas (59.09\%; $P<0.01)$. Regarding functionality, nine out of 16 functional adenomas were positive for cathepsin B $(56.25 \%)$ (Figure 1D-E; Table 1).

Cathepsin B was upregulated in many cancers and, differently from normal cells (lysosomal location), associated with the cell surface. ${ }^{30}$ The tumoral cathepsin B may further contribute to invasiveness via the activation of several matrix metalloproteinases, or by directly remodeling the extracellular matrix; ${ }^{31}$ furthermore, in human glioma cells, downregulation of cathepsin B induces the upregulation of some proapoptotic genes and the suppression of antiapoptotic genes. ${ }^{25}$

\section{Correlation between APAF-I and cathepsin B expression in pituitary adenomas - relationship with proliferation markers Ki-67 and p53}

In order to investigate APAF-1 and cathepsin B as relevant biomarkers for pituitary tumor therapy, they were assessed separately, together, or in correlation with proliferation index Ki-67 LI, tumor suppressor protein p53, or clinical parameters, respectively. Results are presented in detail in Table 1.

APAF-1 and cathepsin B expression showed an inverse correlation; ten out of 13 cathepsin B-positive samples were negative for APAF-1 (76.92\%; $P<0.01)$, while 13 out of 16

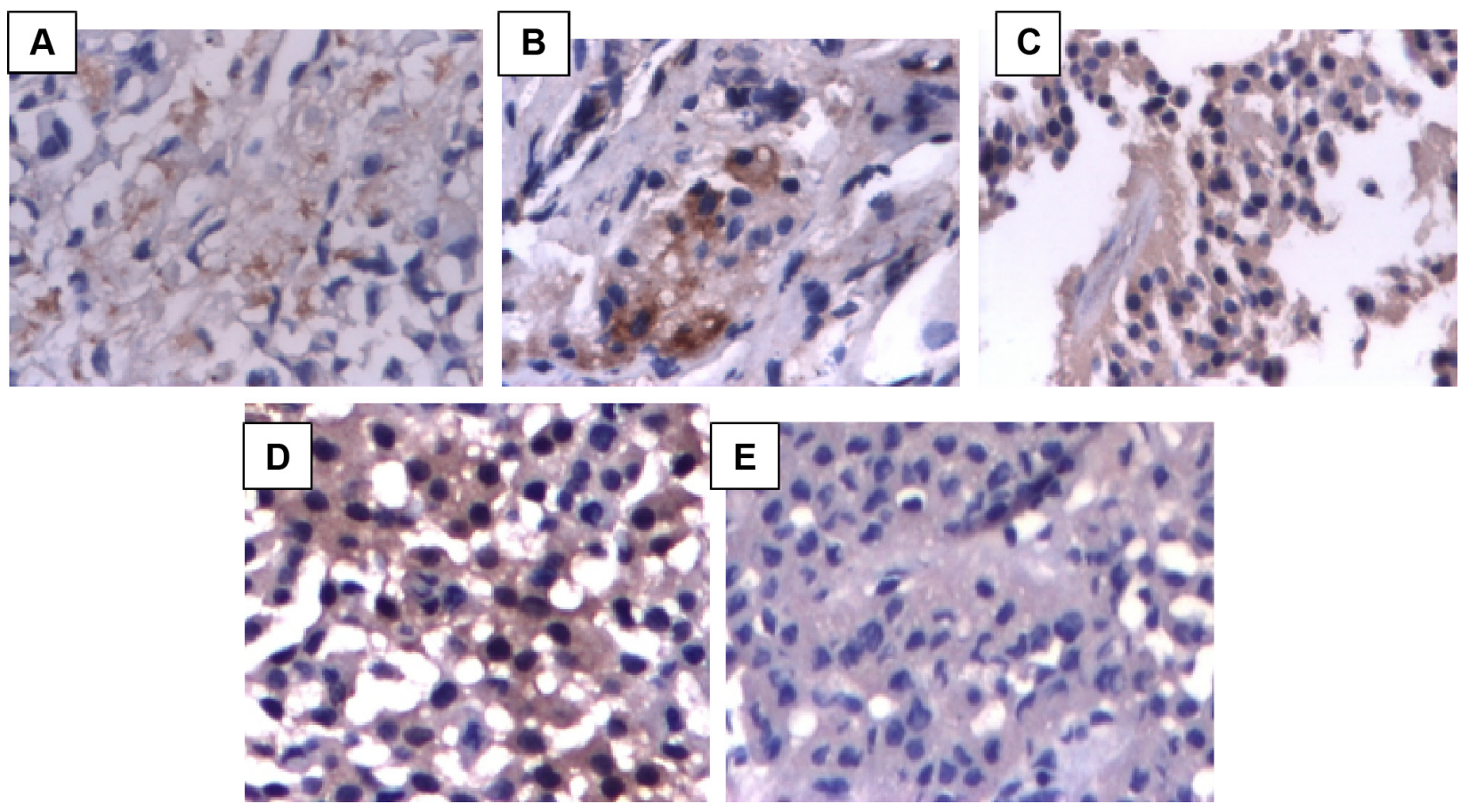

Figure I APAF-I and cathepsin B expression in pituitary adenomas.

Notes: (A) Weak cytoplasmic expression for APAF-I in some dispersed cells in an invasive pituitary adenoma (magnification: 40X); (B) APAF-I-positive expression in moderately invasive pituitary adenoma (magnification: 40x); (C) APAF-I diffuse positive reaction in noninvasive pituitary adenoma (magnification: 40X); (D) cathepsin B cytoplasmic expression in invasive pituitary adenoma (magnification: 40x); (E) cathepsin B negative expression in noninvasive pituitary adenoma (magnification: 40x). Abbreviation: APAF-I, apoptotic protease-activating factor-I. 
Table 2 Correlation between APAF-I, cathepsin B, Ki-67, p53, and various clinicopathological features in patients with pituitary adenomas

\begin{tabular}{|c|c|c|c|c|c|c|c|c|c|}
\hline & \multirow[t]{2}{*}{ Parameters } & \multicolumn{4}{|c|}{ APAF-I } & \multicolumn{4}{|c|}{ Cathepsin B } \\
\hline & & $<\mathbf{2 5} \%$ & $>\mathbf{2 5} \%$ & $\chi^{2}$ & $P$-value & $<\mathbf{5 0} \%$ & $>\mathbf{5 0} \%$ & $\chi^{2}$ & $P$-value \\
\hline \multirow[t]{2}{*}{ Sex } & Male & 9 & 6 & 2.143 & 0.14 & 6 & 9 & 3.394 & 0.065 \\
\hline & Female & 5 & 10 & & & II & 4 & & \\
\hline \multirow[t]{2}{*}{ Age } & $<60$ years & 11 & 13 & 0.033 & 0.85 & 14 & 10 & 0.136 & 0.712 \\
\hline & $>60$ years & 3 & 3 & & & 3 & 3 & & \\
\hline \multirow[t]{2}{*}{ Invasiveness } & Invasive & 14 & 8 & 9.54 & 0.002 & 9 & 13 & 8.342 & 0.003 \\
\hline & Noninvasive & 0 & 8 & & & 8 & 0 & & \\
\hline \multirow[t]{2}{*}{ Functionality } & Functional & 11 & 5 & 6.71 & 0.0095 & 7 & 9 & 2.33 & 0.126 \\
\hline & Nonfunctional & 3 & 11 & & & 10 & 4 & & \\
\hline \multirow[t]{2}{*}{ Ki-67 } & $>3 \%$ & 12 & 8 & 4.28 & 0.038 & 8 & 12 & 6.787 & 0.0091 \\
\hline & $<3 \%$ & 2 & 8 & & & 9 & 1 & & \\
\hline \multirow[t]{2}{*}{ p53 } & + & 8 & 2 & 6.696 & 0.0096 & 0 & 10 & 19.61 & $<0.001$ \\
\hline & - & 6 & 14 & & & 17 & 3 & & \\
\hline \multirow[t]{2}{*}{ APAF-I } & $<25 \%$ & & & & & 4 & 10 & 8.438 & 0.00367 \\
\hline & $>25 \%$ & & & & & 13 & 3 & & \\
\hline \multirow[t]{2}{*}{ Cathepsin B } & $>50 \%$ & 10 & 3 & 8.438 & 0.00367 & & & & \\
\hline & $<50 \%$ & 4 & 13 & & & & & & \\
\hline
\end{tabular}

Abbreviation: APAF-I, apoptotic protease-activating factor-I.

APAF-1-positive samples were negative for cathepsin B $(81.25 \% ; P<0.01)$. Our results regarding the downregulation of APAF-1 and the overexpression of cathepsin B in invasive PAs were confirmed by Western blot analysis (Figure 2).

The loss of APAF-1 expression was observed in 12 out of 20 cases with Ki-67 $>3(P<0.05)$. At the same time, cathepsin $\mathrm{B}$ was overexpressed in $60 \%$ of cases presenting Ki-67 $>3(P<0.01)$. Decreased expression of APAF-1 was shown in most of the invasive adenomas with a high proliferation index, while the cathepsin B level was elevated in this group (Figure 3).

\section{A}

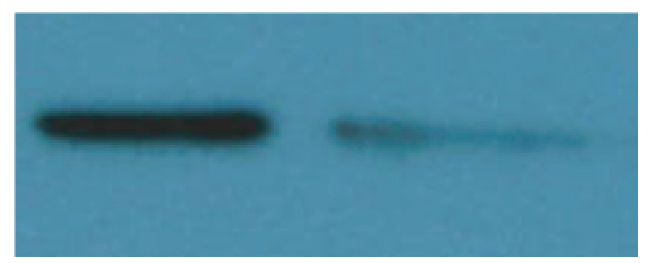

Cathepsin B

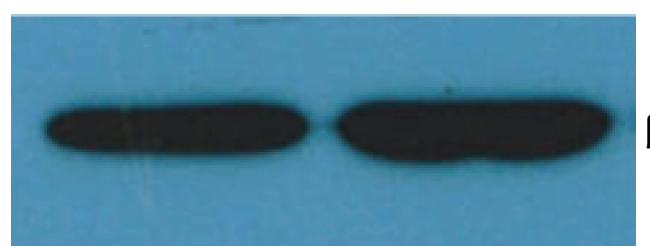

$\beta$-actin

Invasive
Eight out of ten adenomas that were positive for p53 were APAF-1 negative $(80 \%)$, while 14 out of 20 cases with p53 negative expression were APAF-1 positive $(70 \%)(P<0.05)$. While all $\mathrm{p} 53$-positive adenomas presented upregulation in cathepsin B expression, 17 out of 20 cases with p53-negative expression showed a decreased expression for cathepsin $\mathrm{B}(P<0.001)$.

\section{Proteome profiler for apoptosis by array analysis}

In order to establish an overall perspective of the proteins involved in intrinsic and extrinsic apoptotic pathways, we also performed an array analysis of multiple apoptotic proteins.

B

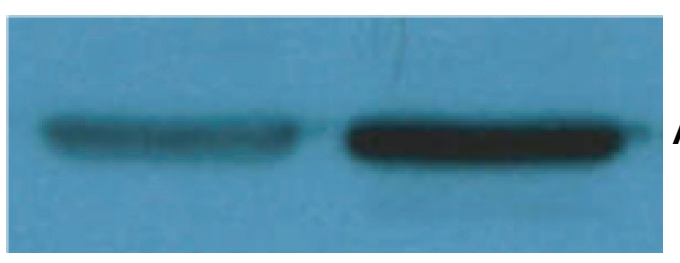

AFAP-1

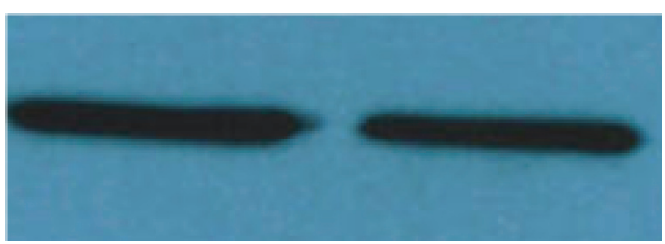

$\beta$-actin
Noninvasive

Figure 2 Validation of (A) cathepsin B and (B) APAF-I expression by Western blot. Abbreviation: APAF-I, apoptotic protease-activating factor-I. 


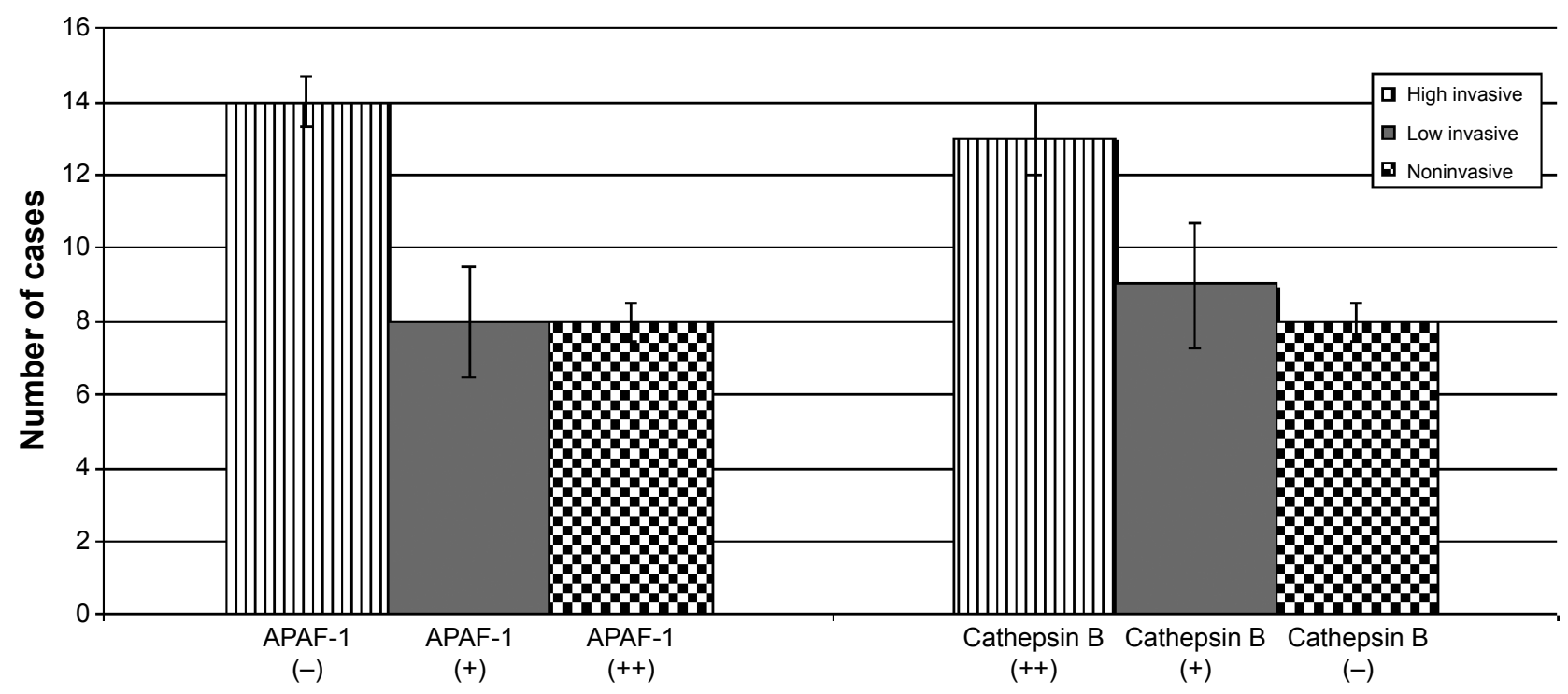

Figure 3 APAF-I and cathepsin B expression in high-invasive, low-invasive, and noninvasive pituitary adenomas. Abbreviation: APAF-I, apoptotic protease-activating factor-I.

Dot blot assay human apoptosis revealed a relevant pattern of expression, detailed in Figure 4 and Figure 5. The results suggest an inhibition of the extrinsic apoptotic pathway in invasive PAs, revealed by a coincident decrease in apoptotic receptor expression for TRAIL-R1, TRAIL-R2, Fas, TNF-R1 (about a 1.5-fold change). Concomitantly, a low expression of proapoptotic proteins Bad, Bax, FADD, HTRA2/ Omi, and SMAC/Diablo was documented. The inhibition of apoptosis in invasive tumors is highlighted by a significant decrease in pro-caspase-3 expression - it was 2.5 -fold

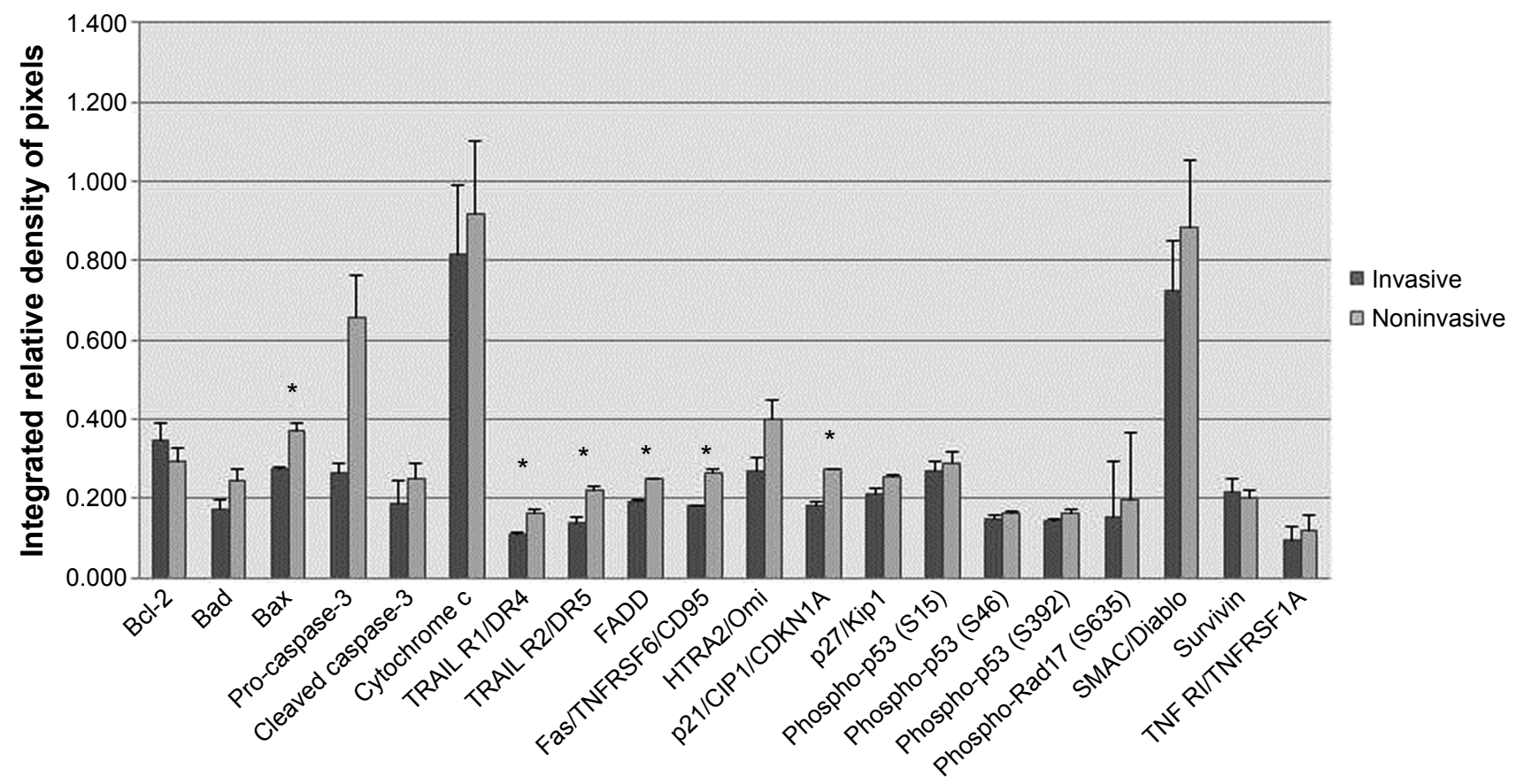

Figure $\mathbf{4}$ Interplay between proliferation and apoptotic pathways in pituitary adenomas.

Note: $* P<0.01$.

Abbreviations: Bcl-2, B-cell lymphoma 2; Bad, Bcl-2-associated death promoter; Bax, Bcl-2-associated X protein; TRAIL-RI/DR4, tumor necrosis factor- $\alpha$-related apoptosis-inducing ligand receptor I - death receptor 4; TRAIL-R2/DR5, tumor necrosis factor- $\alpha$-related apoptosis-inducing ligand receptor 2 - death receptor 5; FADD, Fas-associated protein with death domain; SMAC/Diablo, second mitochondria-derived activator of caspases; TNF-RI, tumor necrosis factor receptor I. 


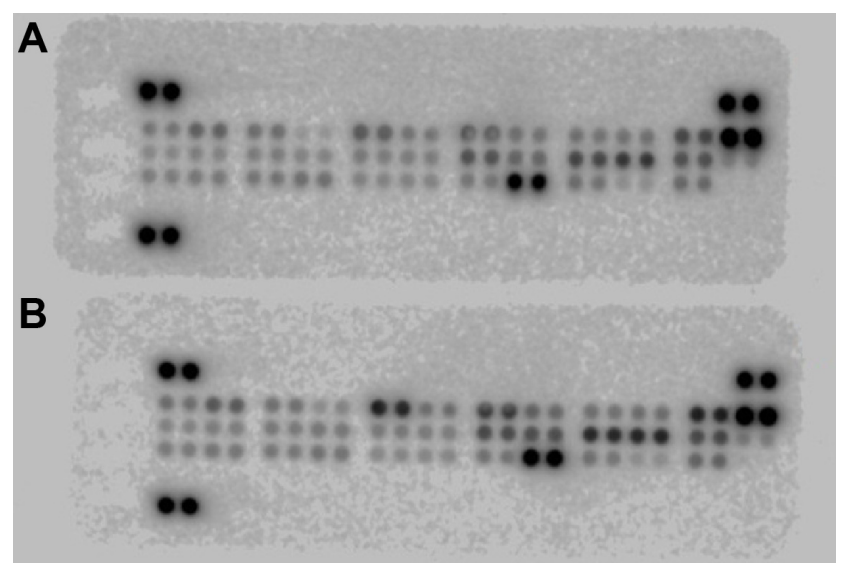

Figure $\mathbf{5}$ The original blots of proteome analysis in $(\mathbf{A})$ invasive and $(\mathbf{B})$ noninvasive pituitary adenomas.

lower in invasive PA when compared with noninvasive tumors. Further evidence for decreased apoptosis in invasive tumors is the lower level of cytochrome $\mathrm{C}$ expression. Our study shows a higher expression of apoptosis inhibitor Bcl-2 in invasive pituitary tumors. Another observation is the slight increase of survivin protein expression in invasive tumors. The results indicated that invasive PAs are characterized by a decrease in the expression of cell-cycle inhibitors, p2 1 and p27 (about a 1.5-fold change), and the low expression of p-RAD17, which is a protein required for the DNA damageinduced cell-cycle G2 arrest.

\section{Discussion}

In contrast to normal tissue homeostasis, tumoral development is characterized by an alteration of the balance between apoptosis and proliferation. Tumor growth and invasiveness are generally defined by an abnormal increase in mitosis paired with lower apoptotic rates. ${ }^{18}$ The most important mechanisms of apoptosis involve the intrinsic apoptotic pathway - in which the mitochondria play a central part - and the extrinsic pathway, where the caspase cascade is triggered via a receptor-ligand-mediated mechanism. ${ }^{22}$

The importance of apoptosome-related proteins (including APAF-1) as markers of tumor progression has been recognized in several types of solid cancers. ${ }^{32,33}$ Studies show that the roles played by APAF-1 in tumor biology are manifold, and are often different based on tumor type. ${ }^{32,34,35}$ Several reports also stress the role of cathepsin B, showing that, when released from the lysosome, it has a proapoptotic effect. $^{36,37}$

The present study is the first, to our knowledge, to analyze the expression of APAF-1 and cathepsin B in correlation with $\mathrm{Ki}-67$ and p53, which are well-established predictive biomarkers of tumor development. APAF-1 expression was decreased in the most invasive PAs when compared with noninvasive ones. Low expression of APAF-1 was also characteristic of adenomas with a high proliferation index. Cathepsin B was expressed in more than half of the analyzed tumors, and was frequently localized in the plasma membrane, displaying a granular pattern. In relation to tumor invasiveness, an inverse pattern, similar to that with APAF-1, was observed with the expression of cathepsin B. Thus, the data show a negative correlation between APAF-1 and invasiveness $(63.63 \%$ of invasive pituitary tumors were APAF-1 negative), and a positive correlation between cathepsin B and invasiveness (59.09\% of invasive tumors were cathepsin B positive). Our results for APAF-1 suggest that the intrinsic mitochondrial pathway is inactivated in invasive adenomas. At the same time, cathepsin B, an enzyme involved in extracellular matrix degradation, was increased in these aggressive specimens.

Findings in different cancer types revealed similar features of APAF-1 and cathepsin B. Thus, in testicular germ tumors, APAF-1 expression decreased gradually, being correlated with the undifferentiated state of the tumor; ${ }^{35}$ in ovarian cancers, the presence of APAF-1 was mentioned, but with impaired functionality. ${ }^{38}$ Similar results were found in breast adenocarcinomas, where APAF-1 expression was downregulated, especially in tumors with a more severe histological grade. ${ }^{39}$ In colorectal cancers, the reduced expression of APAF-1 was a late event in tumor progression, and it correlated with tumor invasion and metastasis; ${ }^{34}$ APAF-1 was also found to be a potentially useful predictive marker that was positively correlated with better survival rates in patients receiving therapy. ${ }^{32}$

Cathepsin B, a lysosomal protease that promotes tumor inception, development, and metastasis, was reportedly overexpressed in colorectal, prostate, breast, or brain cancers. . $^{257,40,41}$ It was well established that the overexpression of cathepsin B was correlated with the invasive status, enabling extracellular matrix degradation and the epithelialto-mesenchymal transition process. These findings highlight the therapeutic potential of targeting cathepsin $B .{ }^{26,37}$

Our results suggest a positive correlation between the proliferative activity and tumor invasiveness in PAs. At the same time, Ki-67 LI showed a statistical correlation with both APAF-1 $(P<0.05)$ and cathepsin B $(P<0.01)$. Previous data showed that invasive PAs have a higher Ki-67 LI, implying a higher growth rate than noninvasive PAs. ${ }^{15,29,42}$ Our study demonstrates that markers along the extrinsic apoptotic pathway are significantly lower in invasive adenocarcinomas; 
similarly, cell-cycle arrest molecules are lower in invasive adenomas.

Our results suggest an inhibition of the extrinsic apoptotic pathway in invasive PAs, with a concurrent TRAIL-R1, TRAIL-R2, Fas, and TNF-R1 receptor expression decrease, as well as a low protein expression for proapoptotic proteins Bad, Bax, FADD, HTRA2/Omi, and SMAC/Diablo; similar results have been reported in other cancers. ${ }^{43-46}$

Membrane permeabilization is followed by subsequent cytochrome $\mathrm{C}$ release from the mitochondria to the cytosol. Cytochrome C, together with APAF-1, leads to the formation of a multiprotein complex, the apoptosome. This complex recruits and activates initiator caspases, eventually leading to the cleavage of pro-caspase 3 to active executioner caspase-3. Executioner caspases induce a series of changes characteristic of apoptosis. ${ }^{47,48}$ As shown by our protein array data, the inhibition of apoptosis in invasive pituitary tumors is also highlighted by a significant decrease in both pro-caspase-3 and cleaved caspase-3 expression. Further evidence for a lower apoptosis in invasive tumors is the decrease in the level of cytochrome $\mathrm{C}$ expression.

Altered expression of Bcl-2 family proteins was observed in pituitary tumors; Bcl-2 and Bax molecules were reported to play an important role in the regulation of apoptotic mechanisms. ${ }^{10,12,49,50}$ Our results are consistent with data showing that proapoptotic proteins Bax and Bad are low-expressed in invasive, as compared to noninvasive, adenomas. ${ }^{51}$ The cell's decision to undergo apoptosis is determined by interactions between the three factions of the Bcl-2 protein family. ${ }^{52} \mathrm{~A}$ higher expression of antiapoptotic Bcl-2 in invasive pituitary tumors has also been revealed accordingly in our study. Increased levels of Bcl-2 expression are associated with microvessel density, linking angiogenesis to the ability of tumor cells to survive, and they are also found in PA cells of murine models. ${ }^{53}$

An interesting outcome of our study was that invasive PAs are characterized by a decreased expression of cellcycle inhibitors p21 and p27, and by the low expression of p-RAD17, a protein required for the DNA damage-induced cell-cycle G2 arrest. Decreased activity of p21 and p27 is suggesting that, in PAs, the invasive potential is paired with uninhibited tumor growth. Moreover, p21 (cip1/waf1) and p27 (kip1), two cyclin-dependent kinase inhibitors, are commonly downregulated in many human cancers, being correlated with poor prognosis. In vivo studies showed that p21 and p27 are involved in the prevention of tumor cell proliferation in glandular tissue neoplasms, including in the pituitary. Furthermore, p21p27-deficient mice present with high tumor incidence, multiorgan hyperplasia, and pituitary tumors, suggesting a collaboration between p21 and p27 in carcinogenesis inhibition. ${ }^{54,55}$

We observed a slight increase of survivin protein expression in invasive tumors. Survivin is an important inhibitor of apoptosis and the overexpression of survivin has been associated with invasiveness and proliferation in pituitary tumors. ${ }^{56-58}$

The approach of a multiparameter panel of pro- and antiapoptotic molecules may lead to a better understanding of the apoptotic-proliferation balance and may prove to be a useful tool in targeted therapy.

\section{Conclusion}

To sum up, our results revealed a negative correlation between APAF-1 and invasiveness, and a positive correlation between cathepsin $\mathrm{B}$ expression and the invasive potential of PAs. A bidirectional and inverted relationship between APAF-1 and cathepsin B expression was noticed.

APAF-1 and cathepsin B, alongside other important apoptotic molecules and in correlation with well-established markers of tumor status, such as Ki-67 and p53, may represent a valuable panel for assessing PA behavior. The shift of balance between APAF-1 and cathepsin B as functional proteins in apoptosis, might be associated with changes in tumor behavior and suggests a possible use in diagnosis and follow up, as well as for potential therapeutic targets.

\section{Acknowledgments}

The research presented in this paper was supported by the grants POS-CCE 685-152/2010, Romania.

This paper is partly supported by the Sectorial Operational Programme Human Resources Development (SOPHRD), financed by the European Social Fund and the Romanian Government under the contract number POSDRU 141531.

The authors present special thanks to Dr Vasile Ciubotaru from the Neurology Department of Bagdasar-Arseni Hospital for providing the samples of patients' tumors, and to Dr Dorel Arsene for providing the pathological diagnosis.

The authors would like to thank Irina Radu, certified translator in Medicine - Pharmacy, certificate credentials: series E number 0048, for professional linguistic assistance.

\section{Disclosure}

The authors report no conflicts of interest in this work.

\section{References}

1. Daly AF, Tichomirowa MA, Beckers A. The epidemiology and genetics of pituitary adenomas. Best Pract Res Clin Endocrinol Metab. 2009; 23(5):543-554.

2. Kopczak A, Renner U, Karl Stalla G. Advances in understanding pituitary tumors. F1000 Prime Rep. 2014;6:5. 
3. Salehi F, Kovacs K, Scheithauer BW, Lloyd RV, Cusimano M. Pituitary tumor-transforming gene in endocrine and other neoplasms: a review and update. Endocr Relat Cancer. 2008;15(3):721-743.

4. Scheithauer BW, Gaffey TA, Lloyd RV, et al. Pathobiology of pituitary adenomas and carcinomas. Neurosurgery. 2006;59(2):341-353; discussion 341-353.

5. Mete O, Ezzat S, Asa SL. Biomarkers of aggressive pituitary adenomas. J Mol Endocrinol. 2012;49(2):R69-R78.

6. Asa SL, Ezzat S. Medical management of pituitary adenomas: structural and ultrastructural changes. Pituitary. 2002;5(2):133-139.

7. Tanase C, Codorean E, Ardeleanu C, et al. Apoptosis in pituitary adenomas; comparative study by flow cytometry and in situ end-labeling technique. Paper presented at: 2nd Intercontinental Congress of Pathology; June 9-13; 2004; Iguassu Falls, Brazil.

8. Tanase C, Ogrezeanu I, Badiu C. Molecular Pathology of Pituitary Adenomas, Chapter Apoptosis 2012.

9. Tanase C, Ogrezeanu I, Badiu C. Molecular Pathology of Pituitary Adenomas, Chapter Proliferation 2012.

10. Kontogeorgos G, Horvath E, Kovacs K, et al. Morphologic changes of prolactin-producing pituitary adenomas after short treatment with dopamine agonists. Acta Neuropathol. 2006;111(1):46-52.

11. Messini I, Kontogeorgos G, Kovacs K, Horvath E, Smyth HS. Pituitary corticotroph adenoma containing many apoptotic cells: a histologic, immunohistochemical, ultrastructural and molecular study. Ultrastruct Pathol. 2002;26(1):27-32.

12. Kontogeorgos G. Predictive markers of pituitary adenoma behavior. Neuroendocrinology. 2006;83(3-4):179-188.

13. Huse JT, Holland EC. Targeting brain cancer: advances in the molecular pathology of malignant glioma and medulloblastoma. Nat Rev Cancer. 2010;10(5):319-331.

14. Elmore S. Apoptosis: a review of programmed cell death. Toxicol Pathol. 2007;35(4):495-516.

15. Pizarro CB, Oliveira MC, Coutinho LB, Ferreira NP. Measurement of Ki-67 antigen in 159 pituitary adenomas using the MIB-1 monoclonal antibody. Braz J Med Biol Res. 2004;37(2):235-243.

16. Thapar K, Scheithauer BW, Kovacs K, Pernicone PJ, Laws ER Jr. p53 expression in pituitary adenomas and carcinomas: correlation with invasiveness and tumor growth fractions. Neurosurgery. 1996 38(4):765-770; discussion 770-771.

17. Vandeva S, Jaffrain-Rea ML, Daly AF, Tichomirowa M, Zacharieva S, Beckers A. The genetics of pituitary adenomas. Best Pract Res Clin Endocrinol Metab. 2010;24(3):461-476.

18. Sav A, Rotondo F, Syro LV, Scheithauer BW, Kovacs K. Biomarkers of pituitary neoplasms. Anticancer Res. 2012;32(11): 4639-4654.

19. Zou H, Henzel WJ, Liu X, Lutschg A, Wang X. Apaf-1, a human protein homologous to $\mathrm{C}$. elegans $\mathrm{CED}-4$, participates in cytochrome c-dependent activation of caspase-3. Cell. 1997;90(3):405-413.

20. Reubold TF, Eschenburg S. A molecular view on signal transduction by the apoptosome. Cell Signal. 2012;24(7):1420-1425.

21. Bao Q, Shi Y. Apoptosome: a platform for the activation of initiator caspases. Cell Death Differ. 2007;14(1):56-65.

22. Guzzo MF, Carvalho LR, Bronstein MD. Apoptosis: its role in pituitary development and neoplastic pituitary tissue. Pituitary. 2014;17(2): 157-162.

23. Fadeel B, Ottosson A, Pervaiz S. Big wheel keeps on turning: apoptosome regulation and its role in chemoresistance. Cell Death Differ. 2008; 15(3):443-452.

24. Tan GJ, Peng ZK, Lu JP, Tang FQ. Cathepsins mediate tumor metastasis. World J Biol Chem. 2013;4(4):91-101.

25. Malla R, Gopinath S, Alapati K, et al. Downregulation of uPAR and cathepsin $\mathrm{B}$ induces apoptosis via regulation of $\mathrm{Bcl}-2$ and $\mathrm{Bax}$ and inhibition of the PI3K/Akt pathway in gliomas. PLoS One. 2010; 5(10): 13731.

26. Reinheckel T, Deussing J, Roth W, Peters C. Towards specific functions of lysosomal cysteine peptidases: phenotypes of mice deficient for cathepsin B or cathepsin L. Biol Chem. 2001;382(5):735-741.
27. Tanase C, Codrici E, Popescu ID, et al. Angiogenic markers: molecular targets for personalized medicine in pituitary adenoma. $\mathrm{Per} \mathrm{Med}$. 2013;10(6):539-548.

28. Ma YY, Yu S, He XJ, et al. Involvement of c-KIT mutation in the development of gastrointestinal stromal tumors through proliferation promotion and apoptosis inhibition. Onco Targets Ther. 2014;7:637-643.

29. Thapar K, Kovacs K, Scheithauer BW, et al. Proliferative activity and invasiveness among pituitary adenomas and carcinomas: an analysis using the MIB-1 antibody. Neurosurgery. 1996;38(1):99-106; discussion 106-107.

30. Elie BT, Gocheva V, Shree T, Dalrymple SA, Holsinger LJ, Joyce JA. Identification and pre-clinical testing of a reversible cathepsin protease inhibitor reveals anti-tumor efficacy in a pancreatic cancer model. Biochimie. 2010;92(11):1618-1624

31. Vasiljeva O, Turk B. Dual contrasting roles of cysteine cathepsins in cancer progression: apoptosis versus tumor invasion. Biochimie. 2008; 90(2):380-386.

32. Hector S, Conlon S, Schmid J, et al. Apoptosome-dependent caspase activation proteins as prognostic markers in Stage II and III colorectal cancer. Br J Cancer. 2012;106(9):1499-1505.

33. Bizzarri M, Proietti S, Cucina A, Reiter RJ. Molecular mechanisms of the pro-apoptotic actions of melatonin in cancer: a review. Expert Opin Ther Targets. 2013;17(12):1483-1496.

34. Paik SS, Jang KS, Song YS, et al. Reduced expression of Apaf-1 in colorectal adenocarcinoma correlates with tumor progression and aggressive phenotype. Ann Surg Oncol. 2007;14(12):3453-3459.

35. Behjati R, Kawai K, Inadome Y, Kano J, Akaza H, Noguchi M. APAF-1 is related to an undifferentiated state in the testicular germ cell tumor pathway. Cancer Sci. 2011;102(1):267-274.

36. Chwieralski CE, Welte T, Bühling F. Cathepsin-regulated apoptosis Apoptosis. 2006;11(2):143-149.

37. Gondi CS, Rao JS. Cathepsin B as a cancer target. Expert Opin Ther Targets. 2013;17(3):281-291.

38. Tan L, Kwok RP, Shukla A, et al. Trichostatin A restores Apaf-1 function in chemoresistant ovarian cancer cells. Cancer. 2011;117(4):784-794.

39. Vinothini G, Murugan RS, Nagini S. Mitochondria-mediated apoptosis in patients with adenocarcinoma of the breast: Correlation with histological grade and menopausal status. Breast. 2011;20(1):86-92.

40. Chan AT, Baba Y, Shima K, et al. Cathepsin B expression and survival in colon cancer: implications for molecular detection of neoplasia. Cancer Epidemiol Biomarkers Prev. 2010;19(11):2777-2785.

41. Gole B, Durán Alonso MB, Dolenc V, Lah T. Post-translational regulation of cathepsin B, but not of other cysteine cathepsins, contributes to increased glioblastoma cell invasiveness in vitro. Pathol Oncol Res. 2009;15(4):711-723.

42. Bosman F, Carneiro F, Hruban R, Theise N. WHO Classification of Tumours of the Digestive System. 4th ed. Geneva, Switzerland: World Health Organization; 2010.

43. Suzuki-Karasaki M, Ochiai T, Suzuki-Karasaki Y. Crosstalk between mitochondrial ROS and depolarization in the potentiation of TRAIL-induced apoptosis in human tumor cells. Int J Oncol. 2014; 44(2):616-628.

44. Chen L, Zhuang G, Li W, Liu Y, Zhang J, Tian X. RGD-FasL induces apoptosis of pituitary adenoma cells. Cell Mol Immunol. 2008;5(1):61-68.

45. Dent P. FADD the bad in head and neck cancer. Cancer Biol Ther. 2013; 14(9):780-781.

46. Tourneur L, Chiocchia G. FADD: a regulator of life and death. Trends Immunol. 2010;31(7):260-269.

47. Galluzzi L, Vitale I, Abrams JM, et al. Molecular definitions of cell death subroutines: recommendations of the Nomenclature Committee on Cell Death 2012. Cell Death Differ. 2012;19(1):107-120.

48. Murphy ÁC, Weyhenmeyer B, Schmid J, et al. Activation of executioner caspases is a predictor of progression-free survival in glioblastoma patients: a systems medicine approach. Cell Death Dis. 2013;4:e629.

49. Sambaziotis D, Kapranos N, Kontogeorgos G. Correlation of bcl-2 and bax with apoptosis in human pituitary adenomas. Pituitary. 2003;6(3): $127-133$. 
50. Chipuk JE, Moldoveanu T, Llambi F, Parsons MJ, Green DR. The BCL-2 family reunion. Mol Cell. 2010;37(3):299-310.

51. Nagy Z, Gatter KC, Esiri MM, Wass JA, Harris AL. Proliferation, bcl-2 expression and angiogenesis in pituitary adenomas: relationship to tumour behaviour. Br J Cancer. 2000;82(8):1441-1445.

52. Adams JM, Cory S. The Bcl-2 apoptotic switch in cancer development and therapy. Oncogene. 2007;26(9):1324-1337.

53. Han L, Wu C, Riaz H, et al. Characterization of the mechanism of inhibin $\alpha$-subunit gene in mouse anterior pituitary cells by RNA interference. PLoS One. 2013;8(10):e74596.

54. García-Fernández RA, García-Palencia P, Suarez C, et al. Cooperative role between $\mathrm{p} 21 \mathrm{cip} 1 / \mathrm{waf} 1$ and $\mathrm{p} 27 \mathrm{kip} 1$ in premature senescence in glandular proliferative lesions in mice. Histol Histopathol. 2014; 29(3):397-406.
55. García-Fernández RA, García-Palencia P, Sánchez MÁ, et al. Combined loss of $\mathrm{p} 21$ (waf1/cip1) and $\mathrm{p} 27$ (kip1) enhances tumorigenesis in mice. Lab Invest. 2011;91(11):1634-1642.

56. Jankowska A, Wasko R, Waligorska-Stachura J, et al. Survivin products in pituitary tumors. Neuro Endocrinol Lett. 2008;29(6): 1033-1037.

57. Zhang YC, Gao J, Xin T, Zheng ZM, Teng LZ. Expression of survivin in invasive pituitary adenoma. Saudi Med J. 2008;29(11): 1589-1592.

58. Wasko R, Waligorska-Stachura J, Jankowska A, Warchol JB, Liebert W, Sowinski J. Coexpression of survivin and PCNA in pituitary tumors and normal pituitary. Neuro Endocrinol Lett. 2009;30(4):477-481.

\section{Publish your work in this journal}

OncoTargets and Therapy is an international, peer-reviewed, open access journal focusing on the pathological basis of all cancers, potential targets for therapy and treatment protocols employed to improve the management of cancer patients. The journal also focuses on the impact of management programs and new therapeutic agents and protocols on

\section{Dovepress}

patient perspectives such as quality of life, adherence and satisfaction. The manuscript management system is completely online and includes a very quick and fair peer-review system, which is all easy to use. Visit http://www.dovepress.com/testimonials.php to read real quotes from published authors. 